\title{
Characterization of bone metabolism in hungarian psoriatic arthritis patients: a case-control study
}

Zsófia Pethő ${ }^{1}$, Edit Kalina ${ }^{2}$, Zoltán Pap ${ }^{3}$, Katalin Hodosi ${ }^{4}$, Rebeka Falcsik ${ }^{4}$, Ádám Balogh ${ }^{5}$, Zoltán Szekanecz ${ }^{4}$ and Harjit Pal Bhattoa ${ }^{2^{*}}$ (i)

\begin{abstract}
Background: Skeletal manifestations are predominant in psoriatic arthritis (PsA). The aim of this cross-sectional, case-control study is the complex assessment of areal and volumetric bone mineral density (BMD), fracture risk, vitamin D status and bone turnover markers, and its association with disease-related variables.

Methods: Lumbar spine (L1-L4) and femoral neck (FN) areal, and distal radius (DR) volumetric BMD, 10-year probability of major and hip osteoporotic fracture as assessed by the fracture risk assessment (FRAX) tool, markers of bone metabolism and disease activity were assessed.

Results: Upon comparison of the disease and age- and sex-matched control groups, there was a statistically significant difference in FN areal $\left(0.952(0.607-1.292) \mathrm{g} / \mathrm{cm}^{2}\right.$ vs. $\left.1.016(0.760-1.550) \mathrm{g} / \mathrm{cm}^{2} ; p=0.001\right)$ and DR total volumetric (284.3 (138.9-470.3) mg/cm ${ }^{3}$ vs. $\left.367.0(287.0-412.0) \mathrm{mg} / \mathrm{cm}^{3} ; p<0.001\right) \mathrm{BMD}, 10$ year probability for major osteoporotic $(3.7 \%(0.7-32 \%)$ vs. $2.6 \%(0-17.5 \%) ; p=0.003)$ and hip $(0.4 \%(0-16 \%)$ vs. $0.05 \%(0-6.1 \%) ; p=0.002)$ fracture and $25-$ hydroxyvitamin D status (47.5 (10-120) nmol/L vs. 64 (10-137; $p<0.001) \mathrm{nmol} / \mathrm{L})$. As compared to areal assessment, volumetric BMD measurements identified a significantly higher number of patients with low bone mineral density (T-Score $\leq-1.00)$ (34\% vs. 88\%, $p<0.001)$. Upon multiple linear regression analysis, disease activity score, as determined by DAS28 assessment, was an independent predictor of 10-year probability for major osteoporotic fracture $(B(95 \% C l)=1.351(0.379-2.323) ; p=0.007)$.

Conclusion: In the studied PSA cohort, disease activity was an independent predictor of 10-year probability for a major osteoporotic fracture, and complemented assessment of volumetric and areal BMD assured better efficacy at identifying those with low bone mineral density.
\end{abstract}

Keywords: Psoriatic arthritis, Areal and volumetric BMD, FRAX, Bone metabolism, Disease activity

\footnotetext{
*Correspondence: harjit@med.unideb.hu

${ }^{2}$ Department of Laboratory Medicine, Faculty of Medicine, University of

Debrecen, Nagyerdei Blvd. 98, Debrecen H-4032, Hungary

Full list of author information is available at the end of the article
}

(c) The Author(s). 2021 Open Access This article is licensed under a Creative Commons Attribution 4.0 International License, which permits use, sharing, adaptation, distribution and reproduction in any medium or format, as long as you give appropriate credit to the original author(s) and the source, provide a link to the Creative Commons licence, and indicate if changes were made. The images or other third party material in this article are included in the article's Creative Commons licence, unless indicated otherwise in a credit line to the material. If material is not included in the article's Creative Commons licence and your intended use is not permitted by statutory regulation or exceeds the permitted use, you will need to obtain permission directly from the copyright holder. To view a copy of this licence, visit http://creativecommons.org/licenses/by/4.0/. The Creative Commons Public Domain Dedication waiver (http://creativecommons.org/publicdomain/zero/1.0/) applies to the data made available in this article, unless otherwise stated in a credit line to the data. 


\section{Background}

The prevalence of psoriasis is estimated at $1-3 \%$ of the world's population [1]. It is a common skin disease associated with multiple comorbidities and the most prevalent coexisting condition, psoriatic arthritis (PsA) develops in $19.7 \%$ of psoriatic patients [2].

In majority of the patients, arthritis is manifested following psoriasis, and in others, it develops simultaneously or before the appearance of skin lesions [3]. Spinal manifestations resemble those in ankylosing spondylitis, and destructive peripheral joint characteristics resemble those of rheumatoid arthritis [4]. Pathologic de novo bone formation, including joint ankylosis, and syndesmophyte formation, characteristically localize to sites of soft-tissue inflammation surrounding the enthesis [5].

Osteoporosis is a systemic skeletal disease characterized by reduced bone mass, microarchitectural damage and increased fragility of bone [6]. Bone loss is a common comorbidity in chronic inflammatory diseases including PsA [7]. A systematic review by Chandran et al., where 21 studies conducted between 2001 and 2014 were included, highlighted the gap in our current knowledge given the discordant findings reported on the prevalence of low bone mineral density in PsA [8].

Osteoporosis has been operationally defined on the basis of bone mineral density (BMD) assessment. The most widely validated technique to measure $\mathrm{BMD}$ is dual energy X-ray absorptiometry (DXA), and diagnostic criteria based on the T-score for BMD are a recommended criteria for prescription of pharmaceutical interventions in osteoporosis [9]. According to the WHO criteria, osteoporosis is defined as a BMD that lies at least 2.5 SD below young healthy average, and therefore 2.5 or more SD below the average healthy young adult ( $\mathrm{T}$-score $\leq-2.5$ SD) $[10,11]$. A major problem with BMD measurement is that these tests alone are not optimal for the detection of individuals at high risk of fracture [12].

On the other hand, peripheral quantitative computed tomography (pQCT) is excellent at three-dimensional quantification of cortical and trabecular bone at various regions of interest, albeit, is not recommended for conventional diagnostic classification [13]. Recent reports have discussed the techniques' utility in patients suffering from inflammatory rheumatic disease [14, 15].

Fragility fractures are defined as fractures that occur spontaneously or following low-trauma and are potential cause of severe disability along with increased mortality risk [10]. Major advance in fragility fracture risk stratification has been achieved by the development of the fracture risk assessment tool (FRAX). The FRAX tool is based on country specific population-based cohorts that assimilate the risks associated with clinical risk factors (age, sex, body mass index, prior fragility fracture, parental history of hip fracture, steroid use, smoking, alcohol intake, disorders strongly associated with osteoporosis and rheumatoid arthritis) and BMD at the femoral neck [16]. The percentage output is a 10-year probability of hip fracture and the 10-year probability of a major osteoporotic fracture (clinical spine, forearm, hip, or shoulder fracture) [16]. Given the clinical, social and economic burden of osteoporotic fractures, the FRAX tool is considered ideal in identifying those at risk and advancing timely preventive or therapeutic interventions.

Presently, studies on complex assessment of areal and volumetric bone mineral density, fracture risk with the FRAX tool, vitamin D and markers of bone turnover in the same cohort of PsA patients are unavailable and the aim of the present cross-sectional, case-control study is to examine bone metabolism and evaluate its association with disease variables.

\section{Methods}

\section{Patients and controls}

We enrolled a total of 118 patients presenting for regular scheduled follow-up at the Division of Rheumatology, Faculty of Medicine, University of Debrecen, Hungary between September 2017 and June 2018. All were diagnosed with PsA as per the Classification Criteria for Psoriatic Arthritis (CASPAR) [17]. Data from patients with psoriatic arthritis was compared to age- and gender-matched volunteers. The control group was constituted by volunteers from our hospital staff or companions (friends or relatives) accompanying the PsA patients to their routine follow-up visit. All volunteers were briefed verbally about the aim of the study and the procedures involved, and all study participants gave written informed consent. For the control group, inclusion criteria were: generally known to be healthy, community dwelling and ambulatory; and exclusion criteria were known prevalent metabolic bone disease or rheumatological condition, any malignancy, liver or renal disease (routine laboratory results for alkaline phosphatase, gamma-glutamyl transpeptidase, alanine aminotransferase, aspartate aminotransferase, total bilirubin, lactate dehydrogenase, urea, creatinine, uric acid and cholinesterase twice the upper limit of normal resulted in exclusion). Volunteers with the closest dates of birth and blood drawing were selected for pairing with the PsA patients. All participants were Hungarian nationals as assessed by proof of identity. The study was performed according to the Declaration of Helsinki and approved by the Hungarian Scientific Research Council Ethical Committee (approval No. 14804-2/2011/EKU).

\section{Disease activity}

All patients underwent physical examination and disease severity assessment. Disease Activity Score in 28 joints (DAS28), in those with peripheral involvement, Bath 
Ankylosing Spondylitis Disease Activity Index (BASDAI), in those with spinal involvement, and Psoriasis Area and Severity Index (PASI) were calculated [18-20].

\section{Laboratory}

Blood sampling was done after overnight fasting to measure levels of osteocalcin (OC), C-terminal telopeptides of type-I collagen $(\mathrm{CTx})$, procollagen type I amino-terminal propeptide (PINP), parathyroid hormone (PTH) and 25hydroxyvitamin D (25OHD). Serum OC, CTx, PINP and PTH were measured using electrochemiluminescence immunoassay (Roche Diagnostics GmbH, Mannheim, Germany). The automated Liaison DiaSorin total 25OHD chemiluminescence immunoassay (CLIA) (DiaSorin Inc., Stillwater, MN, USA) was used to analyze serum 25OHD. The inter-assay CV was $<4 \%$ for OC (lower detection limit: $0.5 \mu \mathrm{g} / \mathrm{L}$, upper detection limit: $300 \mu \mathrm{g} / \mathrm{L}$ ), $<7 \%$ for CTx (lower detection limit: $0.010 \mu \mathrm{g} / \mathrm{L}$, upper detection limit: $6 \mu \mathrm{g} / \mathrm{L}$ ), $<6 \%$ for PINP (lower detection limit: $5 \mu \mathrm{g} / \mathrm{L}$, upper detection limit: $1200 \mu \mathrm{g} / \mathrm{L}$ ), < $7 \%$ for PTH (lower detection limit: $0.127 \mathrm{pmol} / \mathrm{L}$, upper detection limit: $530 \mathrm{pmol} / \mathrm{L}$ ) and < $7.8 \%$ for $25 \mathrm{OHD}$ (lower detection limit: $10 \mathrm{nmol} / \mathrm{L}$, upper detection limit: $375 \mathrm{nmol} / \mathrm{L}$ ). As suggested by DawsonHughes et al., hypovitaminosis D was defined as $25 \mathrm{OHD}$ levels $<75 \mathrm{nmol} / \mathrm{l}$ [21]. The erythrocyte sedimentation rate (ESR) was assessed with the Westergren method [22] and used in the calculation of the DAS28 score.

\section{Dual energy X-ray absorptiometry (DXA)}

The LUNAR Prodigy (GE-Lunar Corp., Madison, WI, USA) densitometer was used to perform DXA examination to measure L1-L4 lumbar spine and left femoral neck (FN) areal BMD. Using the anatomical spine phantom measured daily, the coefficient of variation $(\mathrm{CV})$ of the technique was $0.8 \%$. Bone mineral density was expressed as a T-score, normalcy, low BMD and osteoporotic BMD were defined according to the WHO classification [11].

\section{Peripheral quantitative computer tomography (pQCT)}

Single-slice $\mathrm{pQCT}$ assessments of the ultradistal region of the left forearm were performed using a Stratec XCT2000 instrument (Stratec Medizintechnik GmbH, Pforzheim, Germany) as described by Juhasz et al. [14]. In summary, distal sites at $4 \%$ of the radius length mainly contain trabecular bone. Peripheral quantitative computer tomography can differentiate between cortical and trabecular bone. Total, trabecular, and cortical BMD values are expressed as $\mathrm{mg} / \mathrm{cm}^{3}$. The applied setting to acquire the image was $0.59 \mathrm{~mm}$ voxel. Analysis was done with the XCT 6.00 B software (Stratec Medizintechnik $\mathrm{GmbH}$, Pforzheim, Germany) with measuring mask set to radius and threshold density to $269 \mathrm{mg} / \mathrm{cm}^{3}$ to define trabecular bone.

\section{Fracture risk assessment tool (FRAX)}

A trained study nurse administered a questionnaire to assess the country-specific FRAX index using the tool available online [16]. The data collected were age, sex, weight, height, non-traumatic fracture in the history, parental history of hip fracture, current smoking and alcohol consumption habits, corticosteroid use, diagnosis of rheumatoid arthritis or any condition known to cause low bone mass and femoral BMD.

\section{Statistical analysis}

Descriptive statistics are presented as median and range. The Kolmogorov-Smirnov test was used to check for normality of distribution. The Wilcoxon signed ranks test was used to compare the age- and gender-matched pairs. The Spearman's $\rho$ was calculated for correlation analysis. Univariate and multiple regression analysis using the stepwise method was used to determine correlations and independent associations between parameters. Dual energy X-ray absorptiometry, pQCT and FRAX parameters were the dependent variables and other parameters were independent variables. The $\beta$ standardized linear coefficients showing linear correlations between two parameters were determined. The $B$ $(95 \% \mathrm{CI})$ regression coefficient indicated independent association between the dependent and independent variable during changes. $p$ values $<0.05$ indicated statistical significance. All analyses were performed using the SPSS Statistics software, version 25.0 (IBM Corps., Armonk, NY, USA).

\section{Results}

Patients $(n=118)$ presenting with psoriatic arthritis, confirming to the CASPAR diagnostic criteria, were included in this cross-sectional, analyst blinded, age- and sex-matched, case-control study [17]. The median age (range) of the patients was 54 (25-85) years, with a women:men ratio of 67:51. The median (range) disease duration for psoriasis and arthritis was 16 (1-72) and 9 (0-39) years, respectively. In a small percentage of the patients $(n=14,12 \%)$, the diagnosis of psoriasis was confirmed following the diagnosis of arthritis (on an average within 5 years). Compared to the controls, L1-L4 areal BMD (1.274 $(0.920-1.760) \mathrm{gm} / \mathrm{cm}^{2}$ vs. 1.170 $\left.(0.793-1.184) \mathrm{gm} / \mathrm{cm}^{2} ; p<0.001\right), \mathrm{FN}$ areal BMD (1.016 $(0.760-1.550) \mathrm{gm} / \mathrm{cm}^{2}$ vs. $0.952(0.607-1.292) \mathrm{gm} / \mathrm{cm}^{2}$; $p=0.001$ ), distal radius (DR) total volumetric BMD (367.0 (287.0-412.0) $\mathrm{gm} / \mathrm{cm}^{3}$ vs. 284.3 (138.9-470.3) $\left.\mathrm{gm} / \mathrm{cm}^{3} ; p<0.001\right)$, DR trabecular volumetric BMD (207.0 (145.0-255.0) gm/ $/ \mathrm{cm}^{3}$ vs. $190.0(63.0-351.5) \mathrm{gm} /$ $\left.\mathrm{cm}^{3} ; p=0.002\right)$, DR cortical volumetric BMD (537.0 $(411.0-537.0) \mathrm{gm} / \mathrm{cm}^{3}$ vs. $365.9(175.8-686.5) \mathrm{gm} / \mathrm{cm}^{3}$; $p<0.001)$ and 25OHD (64 (10-137) nmol/L vs. 47.5 $(10-120) \mathrm{nmol} / \mathrm{L} ; p<0.001)$ was significantly lower, and 
Table 1 Subject characteristics

\begin{tabular}{|c|c|c|c|}
\hline Parameters & All patients $(n=118)$ & All controls $(n=118)$ & $p$ value \\
\hline Age, years (median, range) & $54(25-85)$ & $54(25-85)$ & 1.000 \\
\hline Women:Men & $67: 51$ & $67: 51$ & 1.000 \\
\hline DAS28, \% (median, range) $(n=110)$ & $2.37(0.49-5.85)$ & - & - \\
\hline BASDAI, \% (median, range) $(n=8)$ & $1.42(0.02-3.08)$ & - & - \\
\hline PASI, \% (median, range) & $1.65(0-29.40)$ & - & - \\
\hline Arthritis duration, years (median, range) & $9(0-39)$ & - & - \\
\hline Psoriasis duration, years (median, range) & $16(1-72)$ & - & - \\
\hline FRAX Major, \% (median, range) $(n=100)$ & $3.7(0.7-32)$ & $2.6(0-17.5)$ & 0.003 \\
\hline FRAX Hip, \% (median, range) $(n=100)$ & $0.4(0-16)$ & $0.05(0-6.1)$ & 0.002 \\
\hline 10 year probability of major osteoporotic fracture $\geq 20 \%(n, \%)$ & $1(1 \%)$ & $0(0 \%)$ & - \\
\hline 10 year probability of hip fracture $\geq 3 \%$ (n, \%) & $8(8 \%)$ & $4(4 \%)$ & - \\
\hline L1-L4 areal BMD, g/ $\mathrm{cm}^{2}$ (median, range) & $1.170(0.793-1.184)$ & $1.274(0.920-1.760)$ & $<0.001$ \\
\hline Femoral neck areal BMD, g/ $\mathrm{cm}^{2}$ (median, range) & $0.952(0.607-1.292)\left(n=117^{*}\right)$ & $1.016(0.760-1.550)$ & 0.001 \\
\hline Distal radius total volumetric BMD, mg/cm³ (median, range) & $284.3(138.9-470.3)$ & $367.0(287.0-412.0)$ & $<0.001$ \\
\hline Distal radius trabecular volumetric $\mathrm{BMD}, \mathrm{mg} / \mathrm{cm}^{3}$ (median, range) & $190.0(63.0-351.5)$ & $207.0(145.0-255.0)$ & 0.002 \\
\hline Distal radius cortical volumetric BMD, mg/cm³ (median, range) & $365.9(175.8-686.5)$ & $537.0(411.0-537.0)$ & $<0.001$ \\
\hline Calcium, mmol/L (median, range) & $2.4(2.2-2.7)$ & $2.3(2.1-2.7)$ & $<0.001$ \\
\hline Phosphate, mmol/L (median, range) & $0.96(0.6-1.6)$ & $1.10(0.6-1.51)$ & $<0.001$ \\
\hline Osteocalcin, Mg/L (median, range) & $17.7(5-77)$ & $17.9(8.6-33)$ & 0.186 \\
\hline CTx, $\mu g / L$ (median, range) & $0.255(0.040-1.090)$ & $0.200(0.100-0.510)$ & $<0.001$ \\
\hline PINP, $\mu \mathrm{g} / \mathrm{L}$ (median, range) & $46.2(11.0-253.7)$ & $35.0(8.2-72.5)$ & $<0.001$ \\
\hline PTH, pmol/L (median, range) & $4.52(1.43-11.69)$ & $3.78(1.6-9.6)$ & $<0.001$ \\
\hline 25OHD, nmol/L (median, range) & $47.5(10-120)$ & $64(10-137)$ & $<0.001$ \\
\hline $25 \mathrm{OHD}<75 \mathrm{nmol} / \mathrm{L}$ & $79 \%(n=93)$ & $58 \%(n=68)$ & - \\
\hline $25 \mathrm{OHD}<50 \mathrm{nmol} / \mathrm{L}$ & $49 \%(n=58)$ & $28 \%(n=33)$ & - \\
\hline
\end{tabular}

DAS28 Disease activity Score in 28 joints, BASDAI Ankylosing spondylitis disease activity index, PASI Psoriasis area and severity index, FRAX Major 10-year probability of a major osteoporotic fracture as assessed by the FRAX tool, FRAX Hip 10-year probability of a hip osteoporotic fracture as assessed by the FRAX tool, $B M D$ Bone mineral density, CTx C-terminal telopeptides of type-I collagen, PINP Procollagen type I amino-terminal propeptide, PTH Parathyroid hormone, 25OHD

25-hydroxyvitamin D. *Femoral neck BMD assessment was not performed for one patient as she had bilateral total hip replacement

the 10 year probability for a major osteoporotic fracture (2.6 $(0-17.5) \%$ vs. $3.7(0.7-32) \% ; p=0.003)$ and hip fracture $(0.05(0-6.1) \%$ vs. $0.4(0-16) \%$; $p=0.002)$, CTx $(0.200(0.100-0.511) \mu \mathrm{g} / \mathrm{L}$ vs. $0.255(0.040-1.090) \mu \mathrm{g} / \mathrm{L}$; $p<0.001)$ and PINP (35.0 (8.2-72.5) $\mu \mathrm{g} / \mathrm{L}$ vs. 46.2 $(11.0-253.7) \mu \mathrm{g} / \mathrm{L} ; p<0.001)$ were significantly higher in the PsA group (Table 1). The frequency of normal, low and osteoporotic BMD in PsA patients at different regions of interest is presented in Table 2. Areal and volumetric BMD showed statistically significant correlation with each other (Table 3).

Fracture risk characteristics used in the FRAX tool are presented in Table 4 for PsA patients $(n=100)$ between 40 and 90 years of age. A 10 year probability of $\geq 20 \%$ for major osteoporotic fracture and 10 year probability of $\geq 3 \%$ for hip fracture was observed in $1(1 \%)$ and $8(8 \%)$ patients, respectively. One patient had probability above treatment threshold for both fracture types.

Table 2 T-score categories based on femoral neck and lumbar spine areal bone mineral density (BMD), and distal radius volumetric BMD in PsA patients

\begin{tabular}{llll}
\hline Region of Interest & Normal $(\mathbf{n}, \%)$ & Low Bone Mineral Density $(\mathbf{n}, \%)$ & Osteoporosis $(\mathbf{n}, \%)$ \\
\hline Femoral neck $(n=117)$ & $77(66 \%)$ & $35(30 \%)$ & $5(4 \%)$ \\
L1-L4 lumbar spine & $82(70 \%)$ & $32(27 \%)$ & $4(3 \%)$ \\
Distal Radius (total) & $14(12 \%)$ & $66(56 \%)$ & $38(32 \%)$
\end{tabular}

Normal: T-score $\geq-0.99$; Low Bone Mineral Density: T-score between -1.00 and -2.49 ; Osteoporosis: T-score $\leq-2.50$ 
Table 3 Correlation analysis between areal and volumetric bone mineral density

\begin{tabular}{|c|c|c|c|c|c|c|c|}
\hline & & & Areal & & & Volumetric & I Radius \\
\hline & Region of Interest & & Femoral Neck & L1-L4 & Total & Trabecular & Cortical \\
\hline Areal & Femoral neck & Spearman's $\rho$ & 1.000 & 0.526 & 0.496 & 0.374 & 0.422 \\
\hline & & $p$ value & - & $<0.001$ & $<0.001$ & $<0.001$ & $<0.001$ \\
\hline & L1-L4 & Spearman's $\rho$ & 0.526 & & 0.488 & 0.343 & 0.421 \\
\hline & & $p$ value & $<0.001$ & & $<0.001$ & $<0.001$ & $<0.001$ \\
\hline Volumetric Distal Radius & Distal Radius (total) & Spearman's $\rho$ & 0.496 & 0.488 & & 0.601 & 0.842 \\
\hline & & $p$ value & $<0.001$ & $<0.001$ & & $<0.001$ & $<0.001$ \\
\hline & Trabecular & Spearman's $\rho$ & 0.374 & 0.343 & 0.601 & & 0.377 \\
\hline & & $p$ value & $<0.001$ & $<0.001$ & $<0.001$ & & $<0.001$ \\
\hline & Cortical & Spearman's $\rho$ & 0.422 & 0.421 & 0.842 & 0.377 & \\
\hline & & $p$ value & $<0.001$ & $<0.001$ & $<0.001$ & $<0.001$ & \\
\hline
\end{tabular}

A total of $53(44.9 \%)$ and $62(52.5 \%)$ of the patients were on conventional (Methotrexate, Leflunomide, Hydroxychloroquine or Sulphosalazine) and biologic (Infliximab, Adalimumab, Etanercept, Rituximab, Abatacept, Tocilizumab, Certolizumab, Golimumab or Ustekinumab) disease-modifying anti-rheumatic drugs (DMAR D), respectively, either as monotherapy or in a combination. Three (2.5\%) PsA patients did not receive therapy as they were suffering from malignant conditions (prostate cancer, breast cancer and malignant melanoma).

Upon univariate analysis of the PsA cohort data, patients with lower FN areal BMD were older, with longer

Table 4 Patients' fracture risk characteristics used in the FRAX tool

\begin{tabular}{|c|c|}
\hline Risk Factors & $\begin{array}{l}\text { Patients between } 40 \text { and } 90 \\
\text { years of age }(n=100)\end{array}$ \\
\hline Age, years (median, range) & $57(40-85)$ \\
\hline Male:Female & $42: 58$ \\
\hline Weight (kg) (median, range) & $83(48-125)$ \\
\hline Height (cm) (median, range) & $164.5(150-188)$ \\
\hline Previous Fracture (n, \%) & $22(22 \%)$ \\
\hline Parent Fractured Hip (n, \%) & $4(4 \%)$ \\
\hline Current Smoking (n, \%) & $10(10 \%)$ \\
\hline Glucocorticoids (n, \%) & $20(20 \%)$ \\
\hline Rheumatoid Arthritis (n, \%) & $0(0 \%)$ \\
\hline Secondary Osteoporosis (n, \%) & $16(16 \%)$ \\
\hline Alcohol 3 or more units/day (n, \%) & $0(0 \%)$ \\
\hline $\begin{array}{l}\text { Femoral neck areal BMD, } \mathrm{g} / \mathrm{cm}^{2} \\
\text { (median, range) }(n=99)\end{array}$ & $0.934(0.607-1.251)$ \\
\hline FRAX Major, \% (median, range) & $3.75(0.7-32)$ \\
\hline FRAX Hip, \% (median, range) & $0.4(0-16)$ \\
\hline $\begin{array}{l}10 \text { year probability of major } \\
\text { osteoporotic fracture } \geq 20 \%(n, \%)\end{array}$ & $1(1 \%)$ \\
\hline $\begin{array}{l}10 \text { year probability of hip fracture } \\
\geq 3 \%(n, \%)\end{array}$ & $8(8 \%)$ \\
\hline
\end{tabular}

duration of psoriasis and arthritis disease duration, and those with higher FN areal BMD had higher body mass index (BMI) $(p<0.05)$; women had significantly lower L1-L4 areal BMD $(p<0.05)$; those with lower DR total volumetric BMD were older and had longer menopause duration $(p<0.05)$; older patients and women had lower DR trabecular volumetric BMD and those with higher DR trabecular volumetric BMD had longer fertility duration $(p<0.05)$; those with lower DR cortical volumetric BMD were older $(p<0.05)$; the 10 year probability of major osteoporotic fracture was higher in patients with more severe disease as evaluated by DAS28, longer psoriasis and arthritis disease duration, and menopause duration $(p<0.05)$; and the 10 year probability of hip fracture was higher in patients with longer psoriasis and arthritis disease, and menopause duration, in those on conventional DMARDs and insufficient vitamin D status with $25 \mathrm{OHD}$ levels $<75 \mathrm{nmol} / \mathrm{L}$ or $<50 \mathrm{nmol} / \mathrm{L}(p<$ 0.05) (Table 5).

Multiple linear regression analyses revealed that age was an independent predictor of both areal and volumetric BMD. Additionally, BMI and arthritis disease duration also predicted FN areal BMD, female sex was an independent predictor of DR trabecular volumetric BMD. Disease activity score (DAS28) predicted the 10 year probability of major osteoporotic fracture and conventional DMARD predicted the 10 year probability of hip fracture (Table 6).

The prevalence of hypovitaminosis D $(25 \mathrm{OHD}<75$ $\mathrm{nmol} / \mathrm{L}$ ) was 79 and $58 \%$ in the PsA and control groups, respectively. A significant association was found between hypovitaminosis D and PsA; the odds for PsA patients to suffer with hypovitaminosis D was 2.74 (95\%CI: $1.54-$ $4.85, p<0.001)$.

\section{Discussion}

Both areal and volumetric bone mineral density in our patient population was significantly lower than the age 
Table 5 Comparison of PsA patient subsets by univariable analyses

\begin{tabular}{|c|c|c|c|c|}
\hline \multirow[t]{2}{*}{ Dependent variable } & \multirow[t]{2}{*}{ Independent variable } & \multicolumn{3}{|l|}{ Univariate analysis } \\
\hline & & $B(95 \% \mathrm{Cl})$ & $\beta$ & $p$ value \\
\hline \multirow[t]{4}{*}{ Femoral neck areal BMD } & Age & $-0.003(-0.005--0.001)$ & -0.307 & 0.001 \\
\hline & Psoriasis duration & $-0.002(-0.005-0.000)$ & -0.211 & $<0.001$ \\
\hline & Body Mass Index & $0.004(0.000-0.009)$ & 0.180 & 0.050 \\
\hline & Arthritis duration & $-0.005(-0.008--0.002)$ & -0.286 & 0.002 \\
\hline L1-L4 areal BMD & Sex (women vs. men) & $-0.068(-0.139--0.001)$ & -1.174 & 0.049 \\
\hline \multirow[t]{2}{*}{ Distal radius total volumetric BMD } & Age & $-1.563(-2.397--0.729)$ & -0.326 & $<0.001$ \\
\hline & Menopause duration & $-2.213(-4.070--0.356)$ & -0.352 & 0.021 \\
\hline \multirow[t]{3}{*}{ Distal radius trabecular volumetric BMD } & Age & $-0.836(-1.491--0.181)$ & -0.228 & 0.031 \\
\hline & Sex (women vs. men) & $-24.338(-41.172--7.505)$ & -0.257 & 0.005 \\
\hline & Fertility duration & $2482(0.124-4.480)$ & 0.315 & 0.040 \\
\hline Distal radius cortical volumetric BMD & Age & $-2.116(-3.376--0.857)$ & -0.295 & 0.001 \\
\hline \multirow[t]{5}{*}{10 year probability of major osteoporotic fracture } & DAS28 & $1.351(0.379-2.323)$ & 0.277 & 0.007 \\
\hline & Psoriasis duration & $0.085(0.001-0.170)$ & 0.198 & 0.048 \\
\hline & Arthritis duration & $0.165(0.045-0.286)$ & 0.265 & 0.008 \\
\hline & Menopause duration & $0.348(0.142-0.554)$ & 0.470 & 0.001 \\
\hline & cDMARD vs bDMARD & $-2.890(-5.049--0.731)$ & -0.259 & 0.009 \\
\hline \multirow[t]{6}{*}{10 year probability of hip fracture } & Psoriasis duration & $0.054(0.008-0.100)$ & 0.230 & 0.021 \\
\hline & Arthritis duration & $0.080(0.013-0.146)$ & 0.233 & 0.020 \\
\hline & Menopause duration & $0.178(0.051-0.305)$ & 0.405 & 0.007 \\
\hline & cDMARD vs bDMARD & $-1.664(-2.841--0.487)$ & -0.273 & 0.006 \\
\hline & $<75 \mathrm{nmol} / \mathrm{L}$ vs $\geq 75 \mathrm{nmol} / \mathrm{L} 25 \mathrm{OHD}$ & $-1.800(-3.317--0.284)$ & -0.232 & 0.020 \\
\hline & $<50 \mathrm{nmol} / \mathrm{L}$ vs $\geq 50 \mathrm{nmol} / \mathrm{L} 25 \mathrm{OHD}$ & $-1.405(-2.598--0.213)$ & -0.230 & 0.021 \\
\hline
\end{tabular}

$B M D$ Bone mineral density, DAS28 Disease activity Score in 28 joints, CDMARD Conventional disease-modifying anti-rheumatic drugs, $b D M A R D$ Biologic diseasemodifying anti-rheumatic drugs, 25OHD 25-hydroxyvitamin D

and sex-matched controls. This finding is in agreement with a number of studies that have reported PsA patients with an increased risk of low areal bone mineral density [23-28]. But simultaneously is in disagreement with another series of studies that did not report low areal BMD [29-34]. This dichotomy may be due to the non-consistent comparison groups and reported outcomes. Our finding of FN areal BMD significantly correlating with disease duration supports similar previous findings $[25,32,35]$.

Table 6 Multiple regression analysis of bone mineral density and 10-year fracture probability

\begin{tabular}{|c|c|c|c|c|}
\hline \multirow[t]{2}{*}{ Dependent variable } & \multirow{2}{*}{$\begin{array}{l}\text { Independent } \\
\text { variable }\end{array}$} & \multicolumn{3}{|l|}{ Multivariable analysis } \\
\hline & & $B(95 \% \mathrm{Cl})$ & $\beta$ & $p$ value \\
\hline \multirow[t]{3}{*}{ Femoral neck areal BMD } & Age & $-0.004(-0.006--0.002)$ & -0.334 & $<0.001$ \\
\hline & Body Mass Index & $0.006(0.002-0.011)$ & 0.266 & 0.003 \\
\hline & Arthritis duration & $-0.003(-0.006-0.000)$ & -0.184 & 0.039 \\
\hline Distal radius total volumetric BMD & Age & $-1.563(-2.397--0.729)$ & -0.326 & $<0.001$ \\
\hline \multirow[t]{2}{*}{ Distal radius trabecular volumetric BMD } & Age & $-0.905(-1.538--0.272)$ & -0.247 & 0.005 \\
\hline & Sex (women vs. men) & $-25.947(-42.333--9.560)$ & -0.274 & 0.002 \\
\hline Distal radius cortical volumetric BMD & Age & $-2.116(-3.376--0.857)$ & -0.295 & 0.001 \\
\hline 10 year probability of major osteoporotic fracture & DAS28 & $1.351(0.379-2.323)$ & 0.277 & 0.007 \\
\hline 10 year probability of hip fracture & cDMARD vs. bDMARD & $-1-139(-2.270--0.009)$ & -0.187 & 0.048 \\
\hline
\end{tabular}


Bone mineral density measured by $\mathrm{pQCT}$ have been reported previously by Kocijan et al. [36]. Kocijan et al. reported that trabecular and not cortical density was significantly lower in the patient population as compared to the controls, this finding is in contrast to our results of decreased trabecular and cortical density in the patient population. A probable explanation for this discrepancy may be due to the fact that our patient cohort is older, with longer psoriasis and arthritis disease duration. The present study is the first where areal BMD has been compared to volumetric BMD in PsA patients, with statistically significant correlation between the two methodologies. This finding is in tally with 2 other studies in patients with inflammatory rheumatic disease $[14,15]$.

We observed a significantly increased 10-year probability of both major and hip osteoporotic fractures as assessed by the FRAX tool in the studied cohort with psoriatic arthritis. Probability of fragility fractures has not been reported previously in PsA patients using the FRAX tool. Our probability findings are in concordance with findings where osteoporotic fractures were studied as primary endpoints, reporting higher odds of diagnosis with pathological fractures and elevated risk of all fractures $[23,37,38]$. A cross-sectional study from Spain reported increased prevalence of fragility fractures in postmenopausal PsA patients [29]. A Brazilian study reported longer disease duration as predictor of lowimpact fractures [27]. Nonetheless, an Italian study reported no difference in the prevalence of fragility fractures between cases and controls [39].

Beside known predictors of the 10-year probability of fragility fractures, i.e., age and BMD, our findings suggest that in PsA, severe disease activity as assessed by DAS28 is also a noteworthy risk factor.

Fracture risk assessment using the FRAX tool and DR volumetric BMD measurement are excellent alternatives when FN BMD cannot be measured, as in our study where one patient had total bilateral hip replacement.

Although patients identified as being osteoporotic with FN areal BMD measurement were also classified as osteoporotic with DR volumetric BMD measurement, volumetric measurements identified a significantly greater number of patients with low bone mineral density $(34 \%$ vs. $88 \%, p<0.001)$. Although manufacturer provided German reference population is used to derive the T-score with both methodologies, the absence of agreement has also been reported by Marshall et al. [40].

Fracture risk assessment using the FRAX tool identified more patients deserving anti-osteoporosis treatment as compared to FN areal BMD assessment ( $n=8$ vs. $n=$ 6). Patients with major osteoporotic or hip fracture probability in the intervention range, i.e., $\geq 20 \%(n=8)$ and $\geq 3 \%(n=1)$, respectively, were also osteoporotic when assessed for DR volumetric BMD, nonetheless, a wide discrepancy was noticed as a significant proportion of the cohort with non-intervention level FRAX probability was identified as osteoporotic $(n=28,24 \%)$. The FRAX tool offers optional inclusion of FN areal BMD, and its clinical utility in identification of those at increased risk of fragility fractures may be improved were volumetric BMD values and psoriatic arthritis, as a secondary risk factor, also facilitated in the calculation of fracture probability.

The FRAX tool is designed to assess those between 40 and 90 years of age, given this inherent limitation the fracture probability of the young cannot be assessed. Among those under 40 years of age $(n=18)$, areal FN BMD assessment identified $3(17 \%)$ and DR volumetric BMD examination identified 16 (89\%) psoriatic arthritis patient with low bone density ( $\mathrm{T}$-score $\leq-1.0$ ). Our observation suggests that volumetric BMD assessment better identifies those at increased fracture probability, and offers opportunity to initiate fracture risk reduction intervention promptly at a younger age. The true burden to osteoporosis may be underestimated with areal BMD measurement alone.

Although beyond the scope of this present study, it may be worthwhile to examine the utility of diagnostic imaging techniques such as ultrasonography of the knee and magnetic resonance imaging in PsA disease severity assessment [41-44].

The Hungarian National Healthcare System subsidises antiosteoporotic therapy for those with an osteoporotic $\mathrm{T}$-score, based on the WHO classification (T-score $\leq-$ 2.5), or with FRAX probability of more than 3 and 20\% for hip and major osteoporotic fracture, respectively. Our results suggest that a number of osteoporotic and osteopenic patients deserving fracture risk reducing intervention are missed using areal BMD measurement alone, and as such FRAX assessment.

As compared to the control groups, the studied biochemical markers of bone turnover were significantly elevated suggesting a high bone turnover in the PsA population. This finding is supported by one previous study [45]. Grisar et al. reported that CTx levels were significantly higher in the PsA group as compared to the healthy controls [30]. Szentpetery et al. reported correlation between the studied bone markers and hand BMD [46]. Borman et al. reported correlation between CTx and duration of arthritis and no difference in marker levels comparing patients with and without arthritis [28]. Nonetheless, in our study we found no correlation between the studied parameters and bone markers. The inconsistency in bone marker results in the numerous studies published has been summarized in a review by Jadon et al. [47].

The finding of high prevalence of hypovitaminosis D in our study cohort is in agreement with previous 
studies [45, 48-50]. Nonetheless, no difference in 25OHD levels was reported upon comparison of psoriasis patients with and without arthritis in one previous study and another study found lack of correlation between 25OHD levels and the disease activity score [45, 49]. A predisposition for hypovitaminosis D in the PsA cohort may be due to the debilitating nature of the condition, henceforth, they may involve only in limited physical activity; furthermore, patients may shy away from outdoor activity given the mental burden of the skin manifestations of the disease.

Although not supported by correlation analysis in our study cohort, hypovitaminosis $\mathrm{D}$, high bone turnover and low bone mineral density may contribute to the increased fragility fracture probability in this population.

Our study has limitations. Given the difficulties in getting access to the local population register and absence of commercially available population registers, our control group recruitment method may not have been unbiased. Validation of our results is deemed mandatory optimally with a substantially larger cohort.

A higher number of study participants could have improved the statistical power of our analyses, nonetheless, we report a high 10-year probability of fragility fractures along with an increased prevalence of hypovitaminosis D in a PsA cohort with low bone mineral density and high bone turnover; additionally, the case-control study design minimizes the effect of confounding risk factors.

Although warranting validation, the clinical utility of volumetric BMD examination complemented with traditional DXA-based areal BMD measurement and FRAX assessment, are readily applicable in the PsA patient population and serve as an inexpensive tool in identifying patients with low bone mineral density. Prompt identification, treatment and follow-up of patients at risk would help in reducing the burden of fragility fractures in the PsA patient population.

\section{Conclusion}

In the studied PsA cohort, disease activity was an independent predictor of 10-year probability for a major osteoporotic fracture, and complemented assessment of volumetric and areal BMD assured better efficacy at identifying those with low bone mineral density.

\footnotetext{
Abbreviations

25OHD: 25-hydroxyvitamin D; BASDAl: Bath ankylosing spondylitis disease activity index; bDMARD: Biologic disease-modifying anti-rheumatic drugs; BMD: Bone mineral density; BMI: Body mass index; CASPAR: Classification criteria for psoriatic arthritis; CDMARD: Conventional disease-modifying antirheumatic drugs; CLIA: Chemiluminescence immunoassay; CTx: C-terminal telopeptides of type-I collagen; CV: Coefficient of variation; DAS28: Disease activity score in 28 joints; DXA: Dual energy X-ray absorptiometry; DMAR D: Disease-modifying anti-rheumatic drugs; DR: Distal radius; ESR : Erythrocyte sedimentation rate; FN: Femoral neck; FRAX: Fracture risk assessment; L1-L4: Lumbar vertebrae L1 to L4; OC: Osteocalcin; OTKA: Hungarian national scientific research fund; PASI: Psoriasis area and
}

severity index; PINP: Procollagen type I amino-terminal propeptide; pQCT: Peripheral quantitative computed tomography; PsA: Psoriatic arthritis; PTH: Parathyroid hormone; WHO: World Health Organization

\section{Acknowledgements}

Not applicable.

\section{Authors' contributions}

ZP1 recruited patients, coordinated patient examinations, performed peripheral qCT examinations, administered questionnaires, collected and interpreted data and contributed in writing the manuscript. EK performed the routine laboratory examinations and contributed in writing the manuscript. ZP2 contributed in data collection and writing the manuscript. $\mathrm{KH}$ did the statistical analyses. RF administered questionnaires, contributed in data collection and writing the manuscript, $A B$ conceived the study design and contributed in writing the manuscript. ZS conceived the study design, interpreted data and contributed in writing the manuscript and its critical evaluation. HPB conceived the study design, interpreted data and was a major contributor in writing the manuscript and its critical evaluation. The author(s) read and approved the final manuscript.

\section{Funding}

This work is supported by the Hungarian National Scientific Research Fund (OTKA) K105073 research grant (HPB); by the European Union and the State of Hungary and co-financed by the European Social Fund in the framework of TAMOP-4.2.4.A/2-11/1-2012-0001 'National Excellence Program '(ZS); and by the European Union grants GINOP-2.3.2-15-2016-00015 and GINOP-2.3.215-2016-00050 (ZS). The funding bodies were not involved in the design of the study and collection, analysis, and interpretation of data and in writing the manuscript.

\section{Availability of data and materials}

The datasets used and/or analysed during the current study are available from the corresponding author on reasonable request.

\section{Ethics approval and consent to participate}

All study participants gave written informed consent. The study was performed according to the Declaration of Helsinki and approved by the Hungarian Scientific Research Council Ethical Committee (approval No. 14804-2/2011/EKU)

\section{Consent for publication}

Not applicable.

\section{Competing interests}

The authors declare that they have no competing interests.

\section{Author details}

${ }^{1}$ Kalman Laki Doctoral School of the University of Debrecen, Division of Rheumatology, Department of Internal Medicine, Faculty of Medicine, University of Debrecen, Debrecen, Hungary. ${ }^{2}$ Department of Laboratory Medicine, Faculty of Medicine, University of Debrecen, Nagyerdei Blvd. 98, Debrecen H-4032, Hungary. ${ }^{3}$ Kalman Laki Doctoral School of the University of Debrecen, Department of Traumatology and Hand Surgery, Faculty of Medicine, University of Debrecen, Debrecen, Hungary. ${ }^{4}$ Division of Rheumatology, Department of Internal Medicine, Faculty of Medicine, University of Debrecen, Debrecen, Hungary. ${ }^{5}$ Regional Osteoporosis Center, Department of Obstetrics and Gynecology, Faculty of Medicine, University of Debrecen, Debrecen, Hungary.

Received: 5 September 2020 Accepted: 4 January 2021 Published online: 12 January 2021

\footnotetext{
References

1. Myers WA, Gottlieb AB, Mease P. Psoriasis and psoriatic arthritis: clinical features and disease mechanisms. Clin Dermatol. 2006;24:438-47.

2. Alinaghi F, Calov M, Kristensen LE, Gladman DD, Coates LC, Jullien D, et al. Prevalence of psoriatic arthritis in patients with psoriasis: a systematic review and meta-analysis of observational and clinical studies. Am Acad Dermatol. 2019;80(1):251-265.e19.
} 
3. Gladman DD, Shuckett R, Russell ML, Thorne JC, Schachter RK. Psoriatic arthritis (PSA)--an analysis of 220 patients. Q J Med. 1987;62(238):127-41.

4. Ritchlin CT, Colbert RA, Gladman DD. Psoriatic arthritis. N Engl J Med. 2017; 376(10):957-70.

5. Paine A, Ritchlin C. Bone remodeling in psoriasis and psoriatic arthritis: an update. Curr Opin Rheumatol. 2016;28:66-75.

6. NIH Consensus Development Panel on. Osteoporosis prevention, diagnosis, and therapy. Osteoporosis prevention, diagnosis, and therapy JAMA. 2001; 285(6):785-95

7. Redlich K, Smolen JS. Inflammatory bone loss: pathogenesis and therapeutic intervention. Nat Rev Drug Discov. 2012;11:234-50.

8. Chandran S, Aldei A, Johnson SR, Cheung AM, Salonen D, Gladman DD. Prevalence and risk factors of low bone mineral density in psoriatic arthritis: a systematic review. Semin Arthritis Rheum. 2016;46:174-82.

9. Colman EG, Food and Drug Administration. The Food and Drug Administration's osteoporosis guidance document: past, present, and future. J Bone Miner Res. 2003;18(6):1125-8.

10. Kanis JA. The incidence of hip fracture in Europe. Osteoporos Int. 1993;3:10-5.

11. Kanis JA, Melton LJ 3rd, Christiansen C, Johnston CC, Khaltaev N. The diagnosis of osteoporosis. J Bone Miner Res. 1994;9:1137-41.

12. Assessment of fracture risk and its application to screening for postmenopausal osteoporosis. Report of a WHO study group. Geneva: World Health Organization. WHO Technical Report Series; 1994. p. 843

13. Engelke K, Adams JE, Armbrecht G, Augat P, Bogado CE, Bouxsein ML, et al. Clinical use of quantitative computed tomography and peripheral quantitative computed tomography in the management of osteoporosis in adults: the 2007 ISCD official positions. J Clin Densitom. 2008;11:123-62.

14. Juhasz B, Gulyas K, Horvath A, Petho Z, Bhattoa HP, Vancsa A, et al. Comparison of peripheral quantitative computed tomography forearm bone density versus DXA in rheumatoid arthritis patients and controls. Osteoporos Int. 2017;28:1271-7.

15. Horváth Á, Végh E, Pusztai A, Pethő Z, Hamar A, Czókolyová M, et al. Complex assessment of bone mineral density, fracture risk, vitamin $D$ status, and bone metabolism in Hungarian systemic sclerosis patients. Arthritis Res Ther. 2019;21:274.

16. FRAX ${ }^{\circledR}$ Fracture Risk Assessment Tool. https://www.sheffield.ac.uk/FRAX/. Accessed 25 Nov 2020.

17. Taylor W, Gladman D, Helliwell P, Marchesoni A, Mease P, Mielants H. Classification criteria for psoriatic arthritis: development of new criteria from a large international study. Arthritis Rheum. 2006:54:2665-73.

18. Prevoo ML, Van't Hof MA, Kuper HH, Van Leeuwen MA, Van de Putte LB, Van Riel PL. Modified disease activity scores that include twenty-eight-joint counts: development and validation in a prospective longitudinal study of patients with rheumatoid arthritis. Arthritis Rheum. 1995;38:44-8.

19. Garrett S, Jenkinson T, Kennedy LG, Whitelock H, Gaisford P. Calin a. a new approach to defining disease status in ankylosing spondylitis: the bath ankylosing spondylitis disease activity index. J Rheumatol. 1994;21 (12):2286-91.

20. Fredriksson T, Pettersson U. Severe psoriasis—oral therapy with a new retinoid. Dermatologica. 1978;157:238-44.

21. Dawson-Hughes B, Heaney RP, Holick MF, Lips P, Meunier PJ, Vieth R. Estimates of optimal vitamin D status. Osteoporos Int. 2005;16:713-6.

22. Westergren A. Diagnostic tests: the erythrocyte sedimentation rate range and limitations of the technique. Triangle; The Sandoz Journal of Medical Science. 1957:3:20-5.

23. Kathuria P, Gordon KB, Silverberg Jl. Association of psoriasis and psoriatic arthritis with osteoporosis and pathological fractures. J Am Acad Dermatol. 2017;76:1045-1053.e3.

24. Frediani B, Allegri A, Falsetti P, Storri L, Bisogno S, Baldi F, et al. Bone mineral density in patients with psoriatic arthritis. J Rheumatol. 2001;28:138-43.

25. Attia EA, Khafagy A, Abdel-Raheem S, Fathi S, Saad AA. Assessment of osteoporosis in psoriasis with and without arthritis: correlation with disease severity. Int J Dermatol. 2011;50:30-5.

26. Reddy SM, Anandarajah AP, Fisher MC, Mease PJ, Greenberg JD, Kremer JM, et al. Comparative analysis of disease activity measures, use of biologic agents, body mass index, radiographic features, and bone density in psoriatic arthritis and rheumatoid arthritis patients followed in a large U.S. disease registry. J Rheumatol. 2010;37:2566-72.

27. Nolla JM, Fiter J, Rozadilla A, Gómez-Vaquero C. Bone involvement in psoriatic arthritis. J Rheumatol. 2002;29:1108-9.

28. Borman P, Babaoğlu S, Gur G, Bingol S, Bodur H. Bone mineral density and bone turnover in patients with psoriatic arthritis. Clin Rheumatol. 2008;27:443-7.
29. Riesco M, Manzano F, Font P, García A, Nolla JM. Osteoporosis in psoriatic arthritis: an assessment of densitometry and fragility fractures. Clin Rheumatol. 2013;32:1799-804.

30. Grisar J, Bernecker PM, Aringer M, Redlich K, Sedlak M, Wolozcszuk W, et al. Ankylosing spondylitis, psoriatic arthritis, and reactive arthritis show increased bone resorption, but differ with regard to bone formation. J Rheumatol. 2002;29:1430-6.

31. Harrison BJ, Hutchinson CE, Adams J, Bruce IN, Herrick AL. Assessing periarticular bone mineral density in patients with early psoriatic arthritis or rheumatoid arthritis. Ann Rheum Dis. 2002;61:1007-11.

32. D'Épiro S, Marocco C, Salvi M, Mattozzi C, Luci C, Macaluso L, et al. Psoriasis and bone mineral density: implications for long-term patients. J Dermatol. 2014;41:783-7.

33. Dheda K, Cassim B, Patel N, Mody GM. A comparison of bone mineral density in Indians with psoriatic polyarthritis and healthy Indian volunteers. Clin Rheumatol. 2004;23:89.

34. Cortet B, Trouvé MH, Flipo RM. Bone involvement in psoriatic arthritis. J Rheumatol. 2002;29:1107-8.

35. Busquets N, Vaquero CG, Moreno JR, Vilaseca DR, Narváez J, Carmona L, Nolla JM. Bone mineral density status and frequency of osteoporosis and clinical fractures in 155 patients with psoriatic arthritis followed in a university hospital. Reumatol Clin. 2014;10:89-93.

36. Kocijan R, Finzel S, Englbrecht M, Engelke K, Rech J, Schett G. Differences in bone structure between rheumatoid arthritis and psoriatic arthritis patients relative to autoantibody positivity. Ann Rheum Dis. 2014;73:2022-8.

37. Ogdie A, Harter L, Shin D, Baker J, Takeshita J, Choi HK, et al. The risk of fracture among patients with psoriatic arthritis and psoriasis: a populationbased study. Ann Rheum Dis. 2017;76:882-5.

38. Burge R, Dawson-Hughes B, Solomon DH, Wong JB, King A, Tosteson A. Incidence and economic burden of osteoporosis-related fractures in the United States, 2005-2025. J Bone Miner Res. 2007;22:465-75.

39. Del Puente A, Esposito A, Costa L, Benigno C, Del Puente A, Foglia F, et al. Fragility fractures in patients with psoriatic arthritis. J Rheumatol. 2015;93:36-9.

40. Marshall LM, Lang TF, Lambert LC, Zmuda JM, Ensrud KE, Orwoll ES. Osteoporotic fractures in men (MrOS) research group. Dimensions and volumetric BMD of the proximal femur and their relation to age among older U.S. men. J Bone Miner Res. 2006;21:1197-206.

41. Razek AA, Fouda NS, Elmetwaley N, Elbogdady E. Sonography of the knee joint. J Ultrasound. 2009;12(2):53-60.

42. Razek AA, El-Basyouni SR. Ultrasound of knee osteoarthritis: interobserver agreement and correlation with Western Ontario and McMaster universities osteoarthritis. Clin Rheumatol. 2016;35(4):997-1001.

43. Razek AAKA, Ashmalla GA. Assessment of paraspinal neurogenic tumors with diffusion-weighted MR imaging. Eur Spine J. 2018;27(4):841-6.

44. Razek AAKA, Sherif FM. Diagnostic accuracy of diffusion tensor imaging in differentiating malignant from benign compressed vertebrae. Neuroradiology. 2019;61(11):1291-6.

45. Petho Z, Kulcsar-Jakab E, Kalina E, Balogh A, Pusztai A, Gulyas K, et al. Vitamin D status in men with psoriatic arthritis: a case-control study. Osteoporos Int. 2015;26:1965-70.

46. Szentpetery A, McKenna MJ, Murray BF, Ng CT, Brady JJ, Morrin M, et al. Periarticular bone gain at proximal interphalangeal joints and changes in bone turnover markers in response to tumor necrosis factor inhibitors in rheumatoid and psoriatic arthritis. J Rheumatol. 2013;40:653-62.

47. Jadon DR, Nightingale AL, McHugh NJ, Lindsay MA, Korendowych E, Sengupta R. Serum soluble bone turnover biomarkers in psoriatic arthritis and psoriatic spondyloarthropathy. J Rheumatol. 2015;42:21-30.

48. Touma Z, Eder L, Zisman D, Feld J, Chandran V, Rosen CF, et al. Seasonal variation in vitamin $D$ levels in psoriatic arthritis patients from different latitudes and its association with clinical outcomes. Arthritis Care Res (Hoboken). 2011;63:1440-7.

49. Orgaz-Molina J, Magro-Checa C, Rosales-Alexander UL, Arrabal-Polo MA, Buendía-Eisman A, Raya-Alvarez E, et al. Association of 25-hydroxyvitamin D serum levels and metabolic parameters in psoriatic patients with and without arthritis. J Am Acad Dermatol. 2013;69:938-46.

50. Kincse G, Bhattoa PH, Herédi E, Varga J, Szegedi A, Kéri J, Gaál J. Vitamin D3 levels and bone mineral density in patients with psoriasis and/or psoriatic arthritis. J Dermatol. 2015;42:679-84.

\section{Publisher's Note}

Springer Nature remains neutral with regard to jurisdictional claims in published maps and institutional affiliations. 